\title{
DOENÇA OU CRIMINALIDADE: ANÁLISE DO COMPORTAMENTOS PSICOPÁTICOS NOS HOMICIDAS EM UMA PENITENCIÁRIA ESTADUAL DA REGIÃO SUL
}

\author{
DISEASE OR CRIMINALITY: ANALYSIS OF PSYCHOPATHIC BEHAVIOURS IN \\ HOMICIDES IN A STATE PENITENTIARY OF A SOUTH REGION
}

\author{
Laís Steiner ${ }^{1}$, Karin Martins Gomes ${ }^{2}$, João Luis Brunel ${ }^{3}$
}

\begin{abstract}
RESUMO
O principal objetivo deste estudo foi verificar a presença de psicopatia nos detentos homicidas de uma Penitenciária Estadual da região sul, buscando a identificação de traços de perfil e comportamentos psicopáticos. Métodos: Trata-se de uma pesquisa de natureza qualitativa e quantitativa de caráter exploratório, sendo que foi utilizada a Escala Hare para identificação e análise utilizando o ponto de corte 30 e um questionário aberto. A amostra foi intencional e participaram da pesquisa 20 detentos. Resultados/Discussão: Dos 20 condenados por crime de homicídio, a faixa etária foi de 18 a 50 anos. Pela escala Hare, ocorreu a presença de psicopatia em quatro detentos, representando $20 \%$ da amostra carcerária entrevistada. Foi possível elencar e analisar que as principais características da personalidade dos detentos participantes foram ausência de culpa e incapacidade de aceitar responsabilidade pelos próprios atos, sendo que os principais comportamentos verificados foram impulsividade e transtorno de conduta na infância. Conclusão: Todos os participantes que obtiveram pontuação para psicopatia mostraram desestrutura familiar, agressões, alcoolismo, ausência da figura paterna e abandono.

Palavras-chave: Psicopata; Hare (PCL-R); Homicídio.
\end{abstract}

\begin{abstract}
The main objective of this study was to verify the presence of psychopathy in the homicidal detainees of a State Penitentiary in the southern region, seeking the identification of profile traits and psychopathic behaviours. Methods: This is a qualitative and quantitative research of an exploratory nature, using the Hare Scale for identification and analysis using the cutoff point 30 and an open questionnaire. The sample was intentional and 20 inmates participated in the study. Results / Discussion: Of the 20 convicted for homicide, the age range was 18 to 50 years. On the Hare scale, psychopathy occurred in four detainees, representing $20 \%$ of the

\footnotetext{
${ }^{1}$ Acadêmica do Curso de Psicologia da Universidade do Extremo Sul Catarinense - UNESC.

${ }^{2}$ Professora Doutora do curso de Psicologia da Universidade do Extremo Sul Catarinense - UNESC. E-mail: Email: karin@unesc.net.

${ }^{3}$ Professor Mestre do curso de Psicologia da Universidade do Extremo Sul Catarinense - UNESC.
} 
prison sample interviewed. It was possible to state and analyze that the main characteristics of the detainees' personality were absence of guilt and inability to accept responsibility for their own actions. Being that the main behaviors verified were impulsiveness and conduct disorder in childhood. Conclusion: All participants who scored for psychopathy showed family dysfunction, aggression, alcoholism, absence of paternal figure and abandonment.

Keywords: Psychopathy; Hare (PCL-R); Murder.

\section{INTRODUÇÃO}

A definição do termo psicopatia foi utilizada no contexto forense por Cleckley, em 1988, e elaborado por Robert Hare, em 1991, sendo que este conceito não é exatamente igual ao transtorno antissocial, mesmo que haja diversas semelhanças. As pessoas que possuem psicopatia têm as características do transtorno antissocial, porém o contrário não ocorre necessariamente. (HARE, 2011).

Muitos dos casos que envolvem a psicopatia podem estar relacionados ao homicídio, já que em diversas situações há semelhanças nos indivíduos, porém é importante ressaltar que nem todo o homicida é psicopata, bem como nem todo psicopata é homicida. É necessário avaliar com cuidado cada sujeito e situação.

Assim como coloca Josef et al. (2000), o homicídio é um crime extremamente violento e que desestrutura a sociedade, proporcionando estado de alerta e medo nas pessoas. Da mesma forma, ocorre com a psicopatia, porém de uma maneira mais "ocultada", pois essas pessoas agem de forma cautelosa e, normalmente, resguardada. No entanto, podem causar problemas na mesma proporção que homicidas.

A psicopatia dispõe-se de uma inquietação de personalidade basicamente marcada por um padrão de comportamentos indicadores de menosprezo pelos direitos dos outros, com início na infância ou na adolescência. Segundo Prins (1980), na psicopatia há uma evidente ausência de afetos com incapacidade para expressar sentimentos, num estilo de vida caótico em que se torna clara a falta de consideração e percepção sobre o que possa ser relevante para os outros. (NUNES, 2011).

\section{MÉTODO E INSTRUMENTO}

A pesquisa foi quantitativa e qualitativa, com amostra intencional, onde inicialmente verificou-se a quantidade total de detentos homicidas no local, chegando à quantia de 79 . Pela disponibilidade da instituição e tempo, o diretor e a psicóloga do local, selecionaram os 20 detentos com crimes mais qualificados em termos de tortura e sofrimento. 
Os participantes da pesquisa foram 20 detentos do sexo masculino, com idade entre 18 e 50 anos, que cometeram o crime de homicídio, sendo esses condenados, excluindo-se os que não concordaram e não assinaram o termo de consentimento, os que estavam em tratamento de saúde por qualquer enfermidade, e detentos do sexo feminino.

A coleta de dados foi realizada a partir de um questionário aberto e da Escala Hare (PCL-R), estes foram aplicados individualmente aos reclusos selecionados.

A Escala Hare, ou PCL-R (PsychopathyChecklist - Revised), é um instrumento que tem como objetivo a verificação da psicopatia. Já foi, e continua sendo, a ferramenta mais segura e confiável para a identificação de infratores psicopatas, evidenciando o contexto forense (HARE, 2011).

A Escala Hare é uma entrevista semiestruturada, onde há 20 itens a serem pontuados com enfoque em traços de conduta antissocial e psicopatia. Os itens podem ser avaliados por três pontuações, 0 que significa não se aplicar o item àquele indivíduo, 1 que apresenta aquele indício em certa medida e 2 que indica a presença concreta do item. Os aspectos avaliados incluem mentira patológica, versatilidade criminal, delinquência juvenil, ausência de culpa e remorso, vigarice, entre outros aspectos (HAUCK FILHO; TEIXEIRA; ALMEIDA, 2014).

Como cita Hare (2011), este instrumento tem seus itens subdivididos em fator 1 que refere-se às características elementares dos traços de personalidade que fundamentam o perfil de psicopatia e o fator 2, que indica os comportamentos associados à instabilidade da conduta, sendo compreendido como propensão a ações desviante.

O construtor da escala, Robert Hare, definiu o ponto de corte de 30, na qual permite uma maior margem de erro beta, mais sujeito a falsos negativos. Sendo assim, não se incidiria no erro de pontuar inadequadamente algum sujeito como psicopata. (HARE, 2011). Este ponto de corte (30) foi utilizado nesta pesquisa por ser mais fidedigno.

Foi realizada também a consistência interna para verificar a viabilidade da escala na amostra carcerária em que foi aplicada, uma vez que a mesma corresponde à correlação entre os itens da escala.

Para apresentação dos dados relacionados as características dos participantes, estes, serão identificados por números para preservar o sigilo e a ética.

Em relação à análise de dados quantitativos, foi utilizado o software Statistical Package for Social Science (SPSS) versão 20.0, para verificação estatística descritiva e confiabilidade do estudo. 
A presente pesquisa foi aprovada pelo Comitê de Ética em Pesquisa da Universidade do Extremo Sul Catarinense (CEP), n. 45154215.0.0000.0119.

\section{RESULTADOS E DISCUSSÃO}

Os detentos variaram em faixa etária de 23 a 50 anos de idade, dentre eles, 11 eram reincidentes e 9 eram réus primários, sendo o tempo reclusão variável (desde 11 anos a 63 anos de regime fechado). Geralmente haviam cometido mais crimes além do homicídio qualificado, como, abuso sexual, furto, tráfico de drogas, falsificação de cédulas, roubo, tentativas de homicídio, receptação e porte ilegal de arma.

Com base nos dados alcançados no decorrer das entrevistas, foi possível obter os seguintes resultados através da Escala Hare (Quadro 1):

Quadro 1. Pontuação Total e Quantidade de Pessoas a partir do resultado da Escala Hare.

\begin{tabular}{|c|c|}
\hline Pontuação Total & $\begin{array}{c}\text { Quantidade de } \\
\text { pessoas }\end{array}$ \\
\hline 30,5 & 1 \\
\hline 30 & 3 \\
\hline 27,8 & 1 \\
\hline 27 & 1 \\
\hline 26 & 1 \\
\hline 23 & 1 \\
\hline 21,1 & 1 \\
\hline 20 & 3 \\
\hline 19 & 1 \\
\hline 16,7 & 1 \\
\hline 15 & 2 \\
\hline 12 & 1 \\
\hline 11 & 1 \\
\hline 8,9 & 1 \\
\hline 4,2 & 1 \\
\hline
\end{tabular}

Pode-se observar que dos 20 reclusos ocorreu a presença de psicopatia em quatro deles, representando $20 \%$ da amostra carcerária entrevistada. Morana, quem validou a escala 
Hare para a versão brasileira, utiliza o ponto de corte de valor 23, já que no Brasil não há pena perpétua. No entanto, para melhor qualificar a pesquisa, foi utilizado o ponto de corte padrão de Robert Hare.

Porém se analisarmos pelo ponto de corte utilizado no Brasil podemos perceber que quatro sujeitos obtiveram a pontuação relativamente elevada, entre 27,8 e 23, oito indivíduos alcançaram uma pontuação mediana entre 21,1 e 15 e quatro reclusos tiveram pontuação baixa, variando de 12 a 4,2.

A Escala se subdivide entre itens referentes as características dos traços de personalidade, fator 1, e itens que indicam os comportamentos instáveis, vistos como ações desviantes, que são o fator 2. Dentre estes itens, foram analisados todas as características de todos os participantes, mesmos os que não obtiveram pontuação para a psicopatia, e verificouse a prevalência do fator associado aos traços de personalidade, obtendo a pontuação de 179 , sendo que a diferença com o fator 2 foi mínima, de 3 itens. (Quadro 2)

Quadro 2. Fatores 1 e 2. Valores encontrados na Escala Hare sendo o Fator 1, que se refere a traços de personalidade, o mais presente.

\begin{tabular}{|l|c|}
\hline Fator 1 & 179 \\
\hline Fator 2 & 176 \\
\hline
\end{tabular}

A consistência interna verificou confiabilidade, sendo que, geralmente o alfacronbach varia entre zero e um, sendo que se atingir 0.6 a 0.7 indica confiabilidade aceitável, e acima de 0.8 , boa confiabilidade (Quadro 3).

Quadro 3. Estatísticas de Confiabilidade, os resultados indicam confiabilidade aceitável.

\begin{tabular}{|c|c|}
\hline \multicolumn{2}{|c|}{ Estatísticas de confiabilidade } \\
\hline Alfa de Cronbach & Número de itens \\
\hline 0,794 & 20 \\
\hline
\end{tabular}

De acordo com Vasconcellos (2014), a PCL-R possui eficácia quando utilizada em ambiente carcerário, porém possui suas limitações fora deste âmbito. Muitas questões da escala são para avaliação dentro do próprio ambiente forense, reduzindo a fidedignidade fora 
dele, sendo que é incontestável a circunstância de que há diversos psicopatas agindo na sociedade, manipulando e dilacerando vidas.

Dentre os itens referentes à personalidade, os dois que mais se evidenciaram foram a ausência de remorso e culpa e incapacidade de aceitar responsabilidade pelos próprios atos.

De acordo com Hare (2013), os psicopatas revelam uma impressionante falta de preocupação para com as outras pessoas e com as consequências formidáveis que podem gerar a elas.

$\mathrm{O}$ arrependimento exposto por $75 \%$ dos detentos participantes voltava-se para o seu próprio bem estar. Alguns citavam que se arrependiam de ter feito mal para sua família e até para pessoas que nem sequer sabem quem são, mas sempre focando em si, nas suas perdas e consequências.

Muitos crimes, em média 55\% dos analisados na pesquisa, foram cometidos por traição e vingança, e por esses motivos eles se sentiam fazendo "justiça com as próprias mãos", colocando como culpado o indivíduo que o traiu ou que não ficou ao seu lado. Um dos sujeitos entrevistados, que atingiu a pontuação para a psicopatia, matou sua ex-esposa por têlo traído com seu próprio pai, proferiu 9 facadas na mesma, na presença da filha de 8 anos do casal. Quando questionado quem seria o culpado pela infração, o detento relatou: "Na real todos são culpados, pai e esposa por traição e eu por ter matado. Mas meu pai ainda é o mais culpado, por ser pai”(2). Além disso, o mesmo relatou que está arrependido apenas pelo afastamento que teve dos seus filhos e de sua família, sempre expondo que seu pai e sua esposa não tinham o direito de terem o traído.

Hare (2013) coloca que essa falta e/ou culpa do psicopata está interligada a uma inverosível habilidade de racionalizar suas próprias atitudes e ignorar a responsabilidade pessoal por comportamentos que gerem insatisfação a familiares, colegas, amigos e demais pessoas inseridas nas regras sociais. Em contexto geral, os psicopatas possuem desculpas prontas para suas atitudes e, em algumas situações, negam totalmente que tal fato tenha ocorrido.

Dos vinte entrevistados, quatro alegam não ter cometido crime ou culpam outras pessoas de tê-lo praticado ou julgado de maneira ineficaz, sendo que estes não tiveram pontuação suficiente para caracterizar psicopatia. O recluso (14) diz que "Não cometi nenhum crime, eles mataram o taxista a pedrada e facada e aí eles pegaram e disseram que o terceiro 
participante no crime era eu, só pra livrar o outro cara", o recluso dá detalhes do crime e no mesmo instante alega ter sido vítima de toda a situação.

$\mathrm{O}$ recluso (17), incriminado por ter matado seu enteado de 5 anos enforcado, argumenta "Foi um acidente, bati o carro e no laudo apareceu que eu matei ele asfixiado. Fiquei em coma por uma noite e no dia seguinte fui direto para a delegacia. O delegado que inventou isso, não sei porquê, nem tinha marca de nada".

Este item apresenta uma falta de preocupação com os retornos negativos que seu comportamento, tanto os delitos como os não infracionais, têm nas outras pessoas. O sujeito está mais preocupado com a consequência que aquela atitude terá para si mesmo, do que se a mesma interfere de alguma forma no outro. A falta de remorso pode ser demonstrada de várias formas, podem procurar justificativas para suas atitudes, são capazes de confessar não sentirem culpa, podem negar acusações, etc. (RONCHETTI, 2010).

A incapacidade de aceitar responsabilidade pelos próprios atos é um elemento que apresenta o sujeito como impossibilitado ou que não se permite a assumir a responsabilidade pelos seus atos ou pelas consequências do mesmo. Na maioria das vezes usufrui de desculpas e justificativas sem coerência, para suas ações, podendo sobrepor a culpa em outras pessoas e/ou coisas. Pode, ainda, negar acusações a seu respeito, mesmo que haja eminência. (HARE, 2011).

O caso mais explícito para esse item é do detento (1) indivíduo com a pontuação mais elevada na Escala Hare, com histórico criminal bastante diversificado, matou seu pai com 72 facadas aos 15 anos de idade, já que este era alcoólatra e agredia sua mãe, além de tentar matá-lo com tiros. Está envolvido na vida do crime desde seus 8 anos de idade, seu primeiro delito foi furto. Um de seus roubos envolveu estupro, fez com que a mulher amarrasse seu marido, fizesse almoço para ele, colocasse a lingerie que o mesmo escolherá e mantivesse relação sexual, “A minha vontade era de humilhar o cara, mostrar pra ele como era ruim ser traído. Eu olhava praquela mulher e via a minha esposa. Pedi para colocar uma lingerie, gosto de preta, branca ou vermelha. Tratei ela muito bem, que eu não sei nem se o marido dela tinha tratado ela daquele jeito". Quando questionado se conhecia o "cara" que queria humilhar, o denunciado afirmou que não, mas que mesmo assim acredita que o mesmo já havia traído a esposa.

De acordo com Vasconcellos (2014), pessoas com perfil psicopático não são aptos a experienciar as situações que ocorrem com os outros da mesma forma que os indivíduos não 
portadores deste transtorno. Os psicopatas não captam e assimilam as sensações, os sentimentos, que as outras pessoas possam estar vivenciando, do mesmo jeito que os seres normais.

Como o exemplo citado, o denunciado ainda coloca de uma maneira que estivesse fazendo bem para sua vítima, alegando que talvez ela nunca havia sido tratada daquela forma."Teve uma situação que eu senti uma coisa boa, aquela mulher me falou 'Sabia que você não era tão mal assim' e eu tive um sentimento bom".O entrevistado (1) relata que já leu alguns livros sobre psicopatia e crê ser um doente mental que necessita de tratamento, expõe sua vontade para que o matem dentro da prisão.

Dentre os itens comportamentais analisados a impulsividade foi a característica que mais esteve presente entre os detentos analisados. Segundo Hare (2013), "os psicopatas não costumam passar muito tempo pesando prós e contras de determinada ação ou considerando possíveis consequências. "Eu fiz isso porque me deu vontade" é uma resposta comum."

Apenas um detento entrevistado não obteve pontuação na impulsividade, o restante pontuou relatando que a maioria dos seus crimes é realizado "no calor do momento". O participante (4) comentou que, "Quando acontece algum crime é no momento da raiva, de descontrole emocional'. No entanto, diversos crimes por traição foram premeditados, principalmente traição de mulher com amigo. Eles caracterizam como "talarico" o sujeito que se diz amigo e o trai com sua esposa. Muitos relataram pensamentos semelhantes, que "Talarico merece morrer, ele e a senhora. Merecem tiro bem no meio da testa, porque traição não se faz".

Muitos reclusos relataram não pensar e não sentir nada enquanto estão cometendo um crime, "Não sei dizer o que eu sinto, acho que não sinto nada", "Na hora não me lembrei de nada". Outros relatam sentir adrenalina, "Satisfazia, eu gostava daquela adrenalina. Eu sabia que estava conseguindo respeito e espaço dentro do crime"(3), que em muitos casos nem gostam do crime em si, mas da adrenalina que ele proporciona.

Outro item que apareceu com bastante frequência foi o transtorno de conduta na infância, abrangendo a segunda maior pontuação geral da escala.

A prevalência das pessoas portadoras de psicopatia é que apresentem comportamentos delinquentes com bastante antecedência, idade precoce, conduta esta que implica em fraudes, vandalismo, violência, bullying, sexualidade precoce, mentiras frequentes, agressividade excessiva, manipulação, vadiagem, roubo, entre outros. (HARE, 2013). 
A maioria dos reclusos, mesmo que tenha iniciado a vida criminal na idade adulta, possui um histórico de "arteiro" na infância, apresenta bagunça na escola, ou travessuras na rua, como jogar pedras em carros e/ou ônibus, brigas e discussões, uso de drogas, ou rebeliões, maltrato com animais ou outros aspectos. No entanto, o maltrato com os animais se manteve bastante presente e frequente, muitos davam pauladas, outros enforcavam, jogavam pedras ou os jogavam na parede. O sujeito entrevistado (3) relatou, "Eu pegava os gatos da minha tia, jogava-os no poço ou na parede, e às vezes os enforcava. Mas eram só os gatos". O recluso (8), que obteve pontuação mediana, explicou que, "Já espanquei um gato porque ele roubou meu pedaço de carne e queimei outro gato porque eu não gosto de gatos". $\mathrm{O}$ denunciado (1) evidenciou que "Já maltratei diversos animais, uns três gatos, mais de dez cachorros, galinha, vários outros. Eu dava pedradas e enforcava eles".

Hare (2013, p. 79) afirma que "crueldade contra animais na infância costuma ser sinal de graves problemas emocionais ou comportamentais". Além de, ser trivial que psicopatas na idade adulta contem sobre suas crueldades com os animas, na infância e adolescência, de forma banal e até divertida.

Além dos maus tratos com os animais, 50\% dos entrevistados apresentaram início precoce na vida criminal, com idade variável entre 8 e 17 anos, envolvendo os mais diversos crimes como: roubo, furto, estelionato, porte ilegal de arma, tiroteio por ponto de drogas, trafico de drogas, brigas (com lesões corporais), tentativa de homicídio, homicídio, vandalismo, direção perigosa e sem documento.

O indivíduo (1), além de ter assassinado seu pai com 72 facadas com 15 anos, matou um jovem com 6 facadas, logo que saiu do CIP, onde ficou internado por quarenta e cinco dias após a morte de seu pai. Com esse homicídio, voltou para o CIP e ficou por oito meses, saiu por bom comportamento. Posteriormente, depois de alguns meses, matou outra pessoa por ter "mexido" com sua namorada, proferiu 17 facadas na vítima dentro de um bar. Voltou para o CIP, ficou um ano e seis meses e completou 18 anos. Logo em seguida foi preso por dupla tentativa de homicídio, sua mulher havia lhe traído, sendo que deu 5 facadas nela e 9 facadas no amante.

O recluso (6), expôs que furtava e roubava desde os 08 anos de idade, cometia um crime em seguida do outro. Aos 12 anos a polícia o pegou na escola porque queria furar seu colega com uma tesoura. Aos 13 anos cometeu seu primeiro homicídio, com 14 anos uma tentativa de homicídio e com 15 anos dois homicídios. "Matei uns cinco, tentei matar uns 
quatro e to pagando por um que eu não fiz". Ficou cinco meses no CIP aos 13 anos, por roubo, sendo que na adolescência continha setenta e cinco processos que envolvia, furto, homicídio, tentativa de homicídio, depredação de patrimônio público, drogas, roubo, entre outros.

Albuquerque (2013) faz uma observação importante, para que não se misture e interprete quaisquer safadezas infantis ou a revolta da adolescência com transtorno de conduta. Os comportamentos "levados" ocasionais são naturalmente presente no desenvolvimento, porém as infrações de normas e princípios sociais que durem com frequência por seis meses ou mais podem acarretar em um transtorno de conduta.

De acordo com Pires e Leites (2011), a psicopatologia é caracterizada como um funcionamento mental que proporcione alguma modificação doentia do normal, que provoque alguma alteração na percepção e discriminação entre a realidade e a imaginação.

O acusado (2), com pontuação suficiente para psicopatia, matou sua ex-esposa na presença da própria filha de 8 anos de idade, houve a impulsividade como mostra no transtorno antissocial, mas o egocentrismo e a falta de afetividade se fizeram extremamente presentes nesse contexto. Além do delito já ser brutal, na entrevista não mostra nenhum sentimento além da "vingança". Ainda relatou achar sua pena de 19 anos e 6 meses "um pouco pesada" e afirmar que o grande culpado disso tudo é o seu pai, exaltando ainda mais seu egocentrismo e se posicionando como vítima.

De acordo com Vasconcellos (2014), os fatores decisivos do comportamento de um sujeito com psicopatia são diferentes dos catalogados à conduta de uma pessoa sem. Singelas e casuais expressões provocantes não se transformariam em possibilidade motivadora, em um indivíduo sem psicopatia, para a atitude de atirar e dar fim a vida de outro ser. No entanto, um psicopata que realizar tal comportamento, não o pratica com base em um transtorno gerador de "vozes" em seu próprio cérebro.

De acordo com Morana (2011), há explícita divergência entre o criminoso psicopata e o criminoso "comum". Os psicopatas são portadores de alteração de personalidade, onde há comprometimento da mesma como um todo, e ainda que ocorra o sazonamento psicológico, o sujeito não consegue dominar a individualidade aos sentimentos sociais. Já os criminosos "comuns" manifestam personalidade ativa, tornando-se capaz de averiguar a integridade de alguns fatores da repercussão emocional, que visivelmente possibilita um prognóstico melhor em relação de restauração prisional. 
“Tendências à reincidência são, aproximadamente, duas vezes maiores em psicopatas quando comparados a criminosos comuns. Mas tendências são tendências e não fatos consumados". (VASCONCELLOS, p. 48, 2014).

O detento (4), com pontuação para psicopatia, possui um histórico criminal bastante extenso, mesmo tendo iniciado a vida no crime aos 20 anos e hoje estar com 40. Já foi indiciado por alguns homicídios, latrocínio, fuga, homicídio dentro do sistema carcerário, envolvimento com facção criminosa, entre outros. Sendo que, é reincidente, foi preso a primeira vez em 1996 e afirma "ser do crime".

Os indivíduos psicopatas apresentam recaída criminal três vezes maior do que os não psicopatas, além de indicarem-se quatro vezes mais tendentes a reincidência de delitos cruéis do que os criminosos "comuns". (MORANA, 2011).

Segundo Vasconcellos (2014), por mais que a psicopatia exista em graus divergentes, não há como considerar um psicopata como um ser inimputável, assim sendo, o sujeito deve responder pelos seus crimes. Este transtorno pode ocorrer concomitantemente com a dependência química, uma vez que, o sintoma pertinente à busca de estímulos favorece para que haja uma maior inclusão de substâncias psicoativas. Dessa forma, condições para a inimputabilidade se fariam coerentes apenas se o ato ilícito tivesse ocorrido na manifestação de uma "psicose tóxica".

Os psicopatas não são doentes mentais, não possuem dificuldade alguma de cognição e concepção do universo como um todo ou em compreender a ilegitimidade e crueldade dos comportamentos que possui e ações que pratica. São seres egocêntricos, cujas ações são apenas para satisfazer e beneficiar a si próprio, não pensando na interferência que pode ter na vida dos outros. (PIRES; LEITES, 2011).

O detento (3), com pontuação suficiente para psicopatia, já preso por alguns homicídios e tráfico de drogas, além de diversos crimes que não foram descobertos, afirma que "Na verdade eu consigo ter várias pessoas ao meu lado", além de dizer que gosta tudo do seu jeito. Relatou que praticava crime porque sabia que estava conseguindo seu espaço dentro do crime, crimes geralmente planejados. Seu pensamento era única e exclusivamente em si mesmo enquanto praticava ou planejava o crime, analisava se tal situação lhe traria muitos benefícios e então, o cometia.

A psicopatia é vista como uma deformidade do desenvolvimento, o cérebro indica alterações nas funções que impossibilitam o indivíduo de obter a íntegra construção dos 
papéis da sociabilidade, desprovendo assim o senso ético, sendo impossibilitado de considerar o outro. Portanto, acontece acentuada elevação das funções da individualidade. "Por ser defeito e não doença, não existe, até então, tratamento curativo". (MORANA, 2011).

"As atitudes e os comportamentos do psicopata são, muito provavelmente, resultado de uma combinação de fatores biológicos e forças ambientais" (HARE, p. 173, 2013). Dessa forma, considera-se que o contexto familiar, o ambiente em que o indivíduo se desenvolve, acaba por interferir na sua conduta.

O recluso (6), por exemplo, perdeu sua mãe aos 5 anos, seu irmão mais velho foi atropelado com 28 anos, possui outros quatro irmãos sendo que o mais novo não considera "Eu sou o crime e ele a lei, ele é policial. Ele nunca deu valor pra família”. O mesmo coloca que "a família nunca teve oportunidade de viver junto, meu pai era alcoólatra e quando a mãe faleceu, ele abandonou os filhos, mandou três para abrigo e dois para familiares cuidar". O detento (1) também teve problemas com pai alcoólatra, "Minha criação foi péssima, até culpava Deus pela minha família", ainda relatou que, "Minha mãe era bem 'chucrona', de pouca inteligência. Eu e minha irmã éramos os que mais apanhavam, meu pai bebia demais. Quando ele tava são era a melhor pessoa do mundo, mas quando bebia era a pior. A mãe tentava interferir, mas apanhava junto com a gente dẩ'. O sujeito (1) possui três irmãos mortos, um foi morto por um policial e duas foram mortas por desidratação, "A minha irmã mais velha ao invés de dar mamadeira pras pequenas, ela tomava tudo".

Alguns dos detentos, $40 \%$ da amostra, foram criados sem a presença do pai, em alguns casos a mãe se envolvia com outra pessoa e em outros a criação era apenas da figura materna e dos irmãos. No entanto, quase todos os entrevistados nessa posição, tiveram problemas com os novos companheiros da mãe, mesmo sem conhecer o pai biológico, criaram revoltas e rebeldia.

A maioria dos detentos entrevistados, $75 \%$ da amostra, teve e ainda têm uma relação passiva com a sua família, muitos mantêm o contato até hoje, cresceram em ambiente saudável e na presença dos pais. Porém, não se pode afirmar que o contexto familiar seja o único fator que interfere para a presença de psicopatia, mas pode interferir e potencializar os sintomas não sendo a única e exclusiva causa do problema. 


\section{CONSIDERAÇÕES FINAIS}

A pesquisa permitiu verificar quatro detentos com a presença de psicopatia, atingindo a pontuação 30 ou 30,5 na escala Hare. Além deste achado, foi possível perceber que outros quatro detentos obtiveram a pontuação elevada, mesmo não pontuando para psicopatia, pois para esta pesquisa utilizou-se o ponto de corte de 30 .

As principais características de comportamento e traços de perfil psicopático presentes nos detentos homicidas participantes foram ausência de remorso e culpa, incapacidade de aceitar responsabilidade pelos próprios atos, impulsividade e transtorno de conduta na infância.

O trabalho permitiu a diferenciação entre aspectos da psicopatia dentro do âmbito criminal e da psicopatologia. A psicopatia não é uma doença que há tratamento e uma possível cura, não há alterações no critério de realidade ou qualquer tipo de alucinações e/ou delírios. Este transtorno se assemelha com o transtorno de personalidade antissocial, porém possui características próprias, o que o difere dos outros transtornos.

É importante ressaltar que nem todo psicopata é homicida e nem todo homicida é psicopata, ou seja, os dois perfis possuem fatores em comum, podem ocorrer concomitantemente, porém não é uma regra.

O contexto familiar é um fator de extrema importância, visto que interfere diretamente na elaboração e no desenvolvimento do ser humano como um todo, no entanto temos que elucidar que este é um aspecto somatório e não decisório. Todos os participantes que obtiveram pontuação para psicopatia mostraram desestrutura familiar, agressões, alcoolismo, ausência da figura paterna e, até mesmo, abandono, porém não se pode generalizar e tornar este aspecto como regra.

Ainda que o objetivo desta pesquisa não tenha sido de avaliar o contexto individual de cada sujeito, mas identificar perfil psicopático e traços comportamentais, a escuta ativa fez com que houvesse a percepção única de cada detento.

\section{REFERÊNCIAS}

AMERICAN PSYCHIATRIC ASSOCIATION. DSM-5. Manual diagnóstico e estatístico de transtorno mentais. Traduçãode Maria Inês Corrêa Nascimento. 5. ed. Porto Alegre: Artmed, 2014.

ALBUQUERQUE, Rosangela Nieto de. Transtorno de conduta: A difícil convivência no ambiente familiar e social.Síndromes, São Paulo, v. 1, n. 3, p.3-10, 2013. Disponível 
em: $\quad<$ http://www.faculdadesmontenegro.edu.br/Sindromes_2013.pdf\#page=7>. Acesso em: 05 out. 2015.

CID 10: Classificação de transtornos mentais e de comportamento da CID 10:descrições clínicas e diagnósticas. Coordenação Organização Mundial da Saúde. Porto Alegre: Artmed, p 194-276, 1993.

DAlGAlarRONDO, Paulo. Psicopatologia e semiologia dos transtornos mentais. 2.ed. Porto Alegre: Artmed, 2008, p 438.

FORTH, A. E., KOSSON, D. S., HARE, R. D. Hare psychopathy youth version manual.Canada: Multi-Health Systems, 2003.

GUTMAN, Guilherme. Nem tanto e nem tão pouco: a relação entre homicídio e psicose. Revista Latinoamericana de Psicopatologia Fundamental, São Paulo, v. 13, n. 1, p.144-149, mar. 2010. Disponível em: <http://www.scielo.br/pdf/rlpf/v13n1/13.pdf>. Acesso em: 2 nov. 2014.

HARE, Robert . Escala Hare PCL-R: manual e critérios para pesquisa. São Paulo: Casa do Psicólogo, 2011, 157 p.

HARE, Robert. Sem consciência: o mundo perturbador dos psicopatas que vivem entre nós. Porto Alegre: Artmed, 2013, 240 p.

HAUCK FILHO, Nelson; TEIXEIRA, Marco Antônio Pereira; ALMEIDA, Rosa Maria Martins de. Estrutura fatorial da escala PsychopathyChecklist - Revised (PCL-R): uma revisão sistemática. Avaliação Psicológica, Itatiba, v. 2, n. 13, p.247-256, 2014. Disponível em: <http://pepsic.bvsalud.org/pdf/avp/v13n2/v13n2a12.pdf〉. Acesso em: 30 ago. 2015.

HENRIQUES, Rogério Paes. De Cleckley ao DSM-IV-TR: a evolução do conceito de psicopatia rumo à medicalização da deliquência. Revista Latinoamericana de Psicopatologia Fundamental, São Paulo, v. 12, n. 2, p. 285-302, jun. 2009. Disponível em: <http://www.scielo.br/scielo.php?pid=S141547142009000200004\&script=sci_arttext $>$. Acesso em: 24 mar. 2015.

JOSEF, Flavio et al. Comportamento violento e disfunção cerebral: estudo de homicidas no Rio de Janeiro. Revista Brasileira de Psiquiatria, Rio de Janeiro, v. 3, n. 22, p. 124129, 2000. Disponível em: <http://www.scielo.br/pdf/rbp/v22n3/v22n3a03.pdf>. Acesso em: 2 nov. 2014.

MORANA, Hilda Clotilde. PCL-R: PsychopathyChecklistRevised. Revista de Criminologia e Ciências Penitenciárias, São Paulo, v. 01, n. 1, ago. 2011. Disponível em: <http://www.sap.sp.gov.br/download_files/pdf_files/copen/edicao-01/15 - Artigo D.N. - PCL-R - PsychopathyChecklist Revised.pdf>. Acesso em: 21 set. 2015.

NUNES, Laura Marinha. Sobre a psicopatia e sua avaliação. Arquivos Brasileiros de Psicologia,Rio de Janeiro, v. 2, n. 63, p.1-121, 2011. Disponível em: <http://link.periodicos.capes.gov.br/sfxlcl41?frbrVersion=2\&ctx_ver=Z39.882004\&ctx_enc=info:ofi/enc:>. Acesso em: 28 ago. 2015.

PIRES, Gabriele Lima; LEITES, Marlene Hernandez. Criminosos comuns ou psicopatas? Reidese: Revista eletrônica do instituto sergipano de direito do Estado,Sergipe, p.1-19, 2011. Disponível em: <http://www.reidese.com.br/edicao-032011/criminosos-comuns-ou-psicopatas>. Acesso em: 10 nov. 2014. 
RONCHETTI, Ramiro et al. Inventário de psicopatia de hareversao jovens (PCL:YV): estudo preliminar em amostra adolescente brasileira. Revista Interamericana de Psicologia, v. 44, n. 3, p.536-542, 2010.

SILVA, Roberta Salvador et al. Psicopatia e comportamentos interpessoais em detentos: um estudo correlacional.Avaliação Psicológica, Porto Alegre, v. 2, n. 11, p.239-245, 2012. Disponível em: <http://pepsic.bvsalud.org/pdf/avp/v11n2/v11n2a09.pdf>. Acesso em: 01 set. 2015.

VASCONCELLOS, Silvio José Lemos. O bem, o mal e as ciências da mente: do que são constituídos os psicopatas. São Paulo: Ícone, 2014. 160 p.

VASCONCELLOS, Silvio José Lemos. Psicopatia e reconhecimento de expressões faciais de emoções: uma revisão sistemática. Psicologia: Teoria e Pesquisa, Santa Maria, v. 2, n. 30, p.125-134, 2014. Disponível em: 〈http://www.scielo.br/pdf/ptp/v30n2/01.pdf>. Acesso em: 26 ago. 2015. 